\title{
Effects of weight and body parts of Siamese catfish (Pangasius hypophthalmus) on the nutritional content
}

\author{
*Sudirman, S., Herpandi., Lestari, S.D. and Andayani, W. \\ Fisheries Product Technology, Faculty of Agriculture, Sriwijaya University, Indralaya, Ogan Ilir (OI) - \\ 30669 Palembang, South Sumatra, Indonesia
}

\begin{abstract}
Article history:
Received: 25 November 2017

Received in revised form: 6 January 2018

Accepted: 7 January 2018

Available Online: 24 March 2018

Keywords:

Catfish,

Fatty acids,

Extraction,

GC-FID,

Pangasius hypophthalmus
\end{abstract}

DOI:

https://doi.org/10.26656/fr.2017.2(4).280

\begin{abstract}
The purposes of this study were to determine the nutrition contents and fatty acid profiles in Siamese catfish (Pangasius hypophthalmus) based on weight and body parts (head, body, tail, belly flaps, and fillet). This research was conducted using experimental laboratory methods. The fatty acid profiles were determined using Gas Chromatography Flame Ionization Detector (GC-FID) and the data were analyzed descriptively. The analysis result showed that weight difference and body parts catfish significantly $(p<0.05)$ effected to moisture content, ash, fat, and carbohydrate. Most saturated fatty acids identified in catfish was palmitic acid, which was abundant in the belly flap part of catfish (800-1000) $\mathrm{g}$ and the body part of catfish (1001-1200) g. The most abundant monounsaturated fatty acid (MUFA) in catfish was n-9 fatty acids (oleic acid). While, polyunsaturated fatty acid (PUFA), the $n-6$ fatty acid group (linoleic acid). The $n-3$ essential fatty acid (linolenic acid, EPA and DHA) is not significantly different between the body parts (head, body, tail, belly flap, and fillet) of catfish. The essential fatty acid content was mostly found in catfish (800-1000) $\mathrm{g}$.
\end{abstract}

\section{Introduction}

Fish have been a good source of protein, fat, vitamin, and mineral for the human body. The fat in fish is generally unsaturated fatty acids, safe to eat because the cholesterol content and saturated fatty acid are less than other animals (Almunady et al., 2011). Siamese catfish (Pangasius hypophthalmus) is one of the consumption fish that has high calories and proteins as well as low cholesterol levels compared with farm animal meat, so good to be consumed for health (Prahasta and Masturi, 2008).

Siamese catfish is one of the freshwater fish that is easy to breed and widely consumed in Indonesia because its meat is quite tasty, delicious, and crispy. The production of catfish in Indonesia continues to show an increase every year. The production of industrial-scale catfish is generally a catfish that has been processed into a fillet (boneless fish meat) and has a higher selling value and more attractive to global consumers, especially in the US and Europe. Consumers in Singapore and Malaysia want a catfish processed by a curing process called smoked-catfish with a butterfly form (Ministry of Trade Republic of Indonesia, 2013). In the global trade, there are many varieties of catfish products, such as frozen headless and no tail, skin on fillets, skinless fillets, and breaded fillets (Suryaningrum, 2008).

Catfish that are ready for consumption are generally marketed with 700-1300 g weight of each fish. Catfish processing to fillets generally uses fish with weight from 1000 to $1200 \mathrm{~g}$. The body parts of catfish consumed are utilized by local people of South Sumatra as a special or traditional food, namely "Pindang".

Some research on nutritional content of catfish has been done by several researchers, such as the determination of chemical and physical characteristics of catfish flesh from head, body, and belly of catfish by Ridwan (2010), but research with different weight and body parts (head, body, tail, belly flap and fillet) consumed on Siamese catfish have not been done. Therefore, it is necessary to do research about nutritional content with weight difference and body parts of Siamese catfish (Pangasius hypophthalmus), so it is expected to be used as one of fishery resource information that can fulfill the nutritional requirement, for example, essential fatty acid with high economic value. The aims of this research were to know the chemical composition and fatty acid profiles of Siamese catfish (Pangasius hypophthalmus) with different weight 
and body parts (head, body, tail, belly flap, and fillet).

\section{Materials and methods}

\subsection{Materials}

Materials used in this study were Siamese catfish (Pangasius hypophthalmus), hexane solvents, and chemicals used for analysis. This research was conducted by laboratory experimental method and consisted of two steps. First, the proximate analysis of Siamese catfish that analyzed by Factorial Randomized Block Design and observation variables include moisture, ash, fat, protein, and carbohydrate. Second, the fatty acid of Siamese catfish analysis used Gas ChromatographyFlame Ionization Detector (GC-FID) with descriptive data analysis.

\subsection{Methods}

\subsubsection{Sample preparation}

Siamese catfish (Pangasius hypopthalmus) were taken from Indralaya's traditional market, Ogan Ilir Regency in South Sumatra. Fish obtained in the living conditions carried out the process included grading (weight), wash, and then carried out preparations. Catfish divide based on weight (800-1000 g, 1001-1200 g) and body parts (head, body, tail, belly flap, fillet).

\subsubsection{Proximate analysis}

Proximate analysis was performed to determine the chemical compositions such as moisture content, ash, protein, fat, and carbohydrate. This analysis was determined by the methods described by AOAC (2005).

\subsubsection{Fatty acid profiles}

Fatty acid profile analysis was performed by several steps: fat extraction, hydrolysis, and esterification. Fatty acid component analyzed as FAME by used Gas Chromatography-Flame Ionization Detector (GC-FID).

\section{Results and discussion}

\subsection{Chemical composition}

\subsubsection{Moisture}

The moisture content of catfish fillet shown on Figure 1. The moisture content is increasing along with the increase of the Siamese catfish weight and different on some body parts of Siamese catfish. The water content in Siamese catfish can affect the fat content contained in the fish. The higher the water content in the fish the less the fat content.

Based on Figure 1, the moisture content was between $59.64-80.84 \%$ at $800-1000 \mathrm{~g}$ and $53.55-78.74 \%$ at $1001-$
$1200 \mathrm{~g}$ was the highest. Siamese catfish are freshwater fish that are hypertonic compared to its environment, so the process of osmosis occurs from the environment into the fish body resulting in high water content in freshwater fish (Pramuditha, 2014). In gourami, the increasing weight of fish causes the water content to decrease. Variations in the water content of catfish can be caused by several factors, such as age, metabolic rate and movement of fish (Taufiqurrahman, 2008).

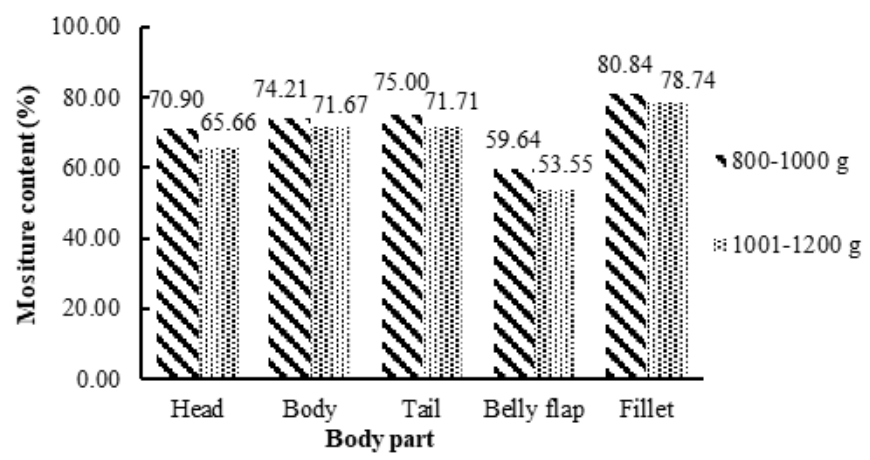

Figure 1. The moisture content of Siamese catfish (Pangasius hypopthalmus) with different weight and body parts.

The water content of the body is significantly different from the water content of other parts of the body, but not significantly different with the water content of the tail. The tail was cut with the size of the fish consumption from the adipose fin to caudal fin, hence, the tail still contained meat from the body. The highest water content was on the fillet and the lowest moisture content was on the belly flap. Siamese catfish fillet analyzed only part of the meat that has been removed skin and fat so that the moisture content is dominant in the fillet, this could be caused by water absorbed in the matrix or tissue in the meat (Kusnandar, 2010). While, the lowest percentage of moisture content was in the belly flap because the belly flap contains more fat, so the water content was lower.

\subsubsection{Protein}

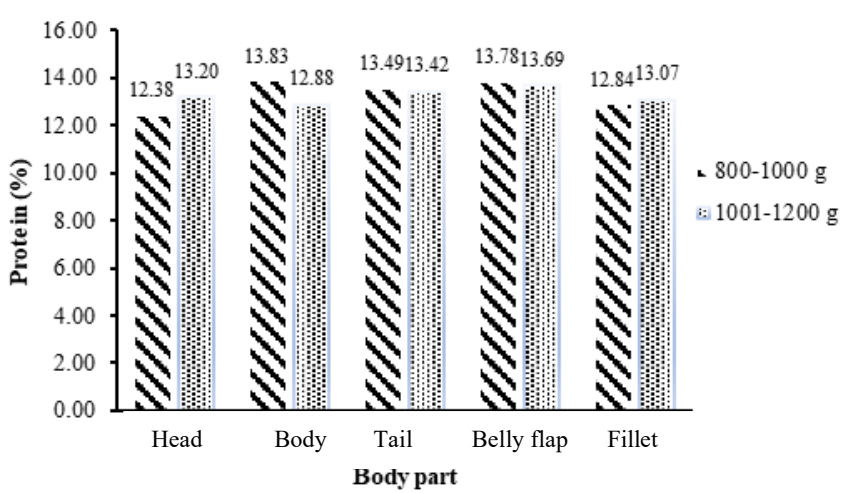

Figure 2. The protein content of Siamese catfish (Pangasius hypopthalmus) with different weight and body parts

The protein content of catfish was 12.38 to $13.83 \%$ at $800-1000 \mathrm{~g}$ whereas at the weight of 1001-1200 $\mathrm{g}$ the protein content ranged from $12.88-13.69 \%$. The highest 
protein content was in the body weight of 800-1000 g, while the lowest protein content was in the head of catfish 800-1000 g (Figure 2). Protein content analyzed did not show differences in each treatment. According to Suwandi et al. (2014), the high protein content in fish flesh is influenced by the type of food, habitat, and food availability.

The treatment with different weight, body part, and interaction of treatments was not significantly different $(p<0.05)$ to the protein content in Siamese catfish. This may indicate that differences in the body weight and body parts of the Siamese catfish do not affect the protein content of Siamese catfish. According to Hafiludin et al. (2014), high protein content in fish only indicates a difference in the frequency of values between each other nutrient content of the total $100 \%$ total nutrient.

\subsubsection{Carbohydrate}

Carbohydrate content of catfish 800-1000 g was significantly different with 1001-1200 g. The highest carbohydrate content found in catfish 1001-1200 g (Figure 3). The carbohydrates content of fish increased with the increasing size of fish. Variations of chemical composition in fishery products are influenced by species of fish, sex, age, weight, fishing ground, season, and types of food (Taufiqurrahman, 2008).

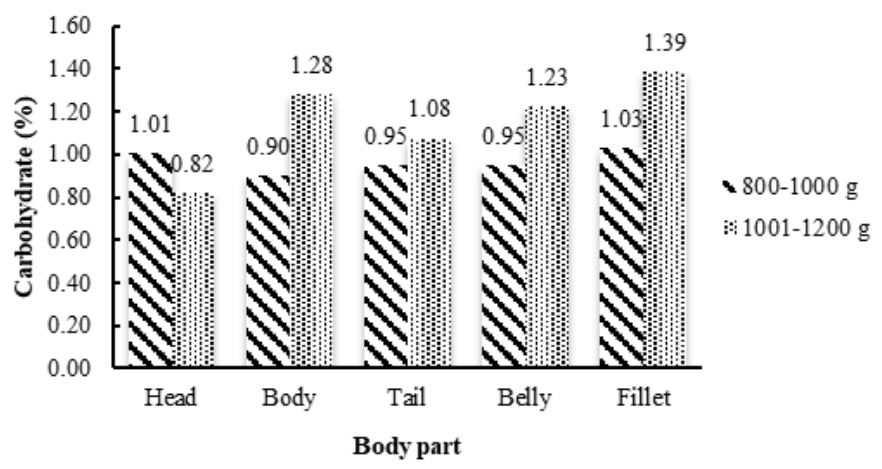

Figure 3. Carbohydrate content of Siamese catfish (Pangasius hypopthalmus) with different weight and body parts.

Carbohydrate levels on head part catfish 1001-1200 $\mathrm{g}$ was significantly different from the carbohydrate levels of other body parts. Carbohydrate content weight of 800$1000 \mathrm{~g}$ of body parts was not significantly different with carbohydrate content weight of $800-1000 \mathrm{~g}$ of the tail and belly part, but significantly different with carbohydrate level in other treatment. The differences in proximate content can be caused by many factors, especially differences in habitat, size, sex and sexual condition of fish (Adawyah, 2007).

\subsubsection{Ash content}

The highest ash content was in body, tail, and fillet of catfish 800-1000 g, while the lowest ash content was in belly flap of catfish 1001-1200 g (Figure 4). The difference of ash content can be influenced based on the different main function of the body parts of fish such as structural and metabolism functions. Differences of ash content also can be affected by the type of food and habitat of the fish. The content of ash contained is influenced by the mineral content found in the living habitat of the fish (Suwandi, 2014). Ash content of catfish 1001-1200 g was significantly different from the ash content of 800-1000 g. The highest ash content found in catfish $800-1000 \mathrm{~g}$. This result was suggested that catfish with lower weight has higher ash content. This difference of ash content of catfish is based on body weight of can be affected by the differences of feed composition and the mineral composition which serves as an agent for new cells, maintain, and replace damaged cells. Minerals are needed as regulators in oxidation processes, normal functions of nerves and muscles, and other processes that occur in the body (Almatsier, 2001).

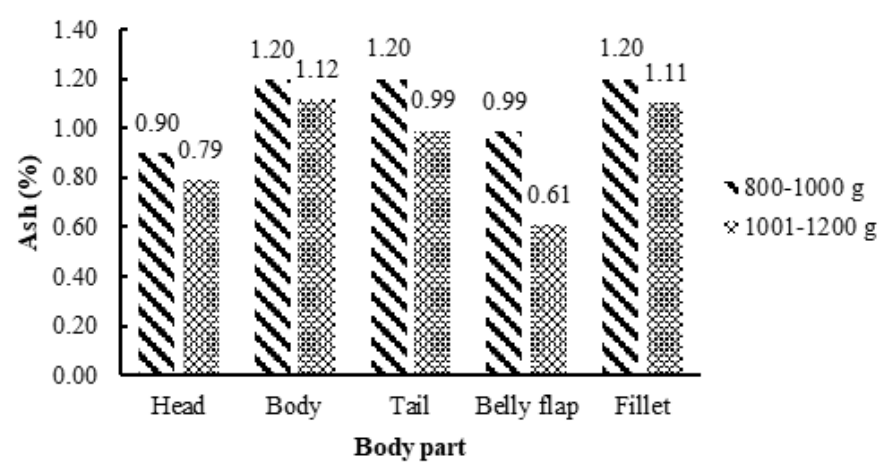

Figure 4. Ash content of Siamese catfish (Pangasius hypopthalmus) with different weight and body parts.

\subsubsection{Fat content}

The fat content of catfish $800-1000 \mathrm{~g}$ from $4.10 \%$ to $24.65 \%$, whereas in catfish $1001-1200 \mathrm{~g}$ was 5.70 $30.93 \%$ (Figure 5). The highest fat content was in the belly flap part of catfish 1001-1200 g, while the lowest fat content was fillet 800-1000 g. Fish fat content inversely with water content, the lower the water content, the higher the fat content. According to Anggraini and Edison (2015), increased levels of body fat fish caused by an increase in fat in the diet increased fat consumed fish and which are not used as a source of energy and then stored as body fat.

The fat content of catfish 800-1000 $\mathrm{g}$ was significantly different with fat content 1001-1200 g. The highest fat content was found in catfish 1001-1200 g. According to Nianda (2008), in adult fish with greater weight has increasing fat content. Low levels of fat in fish with smaller weights are caused because of the fish 
still in the process of growth, need more energy from fat and causes reducing fat stored in the body.

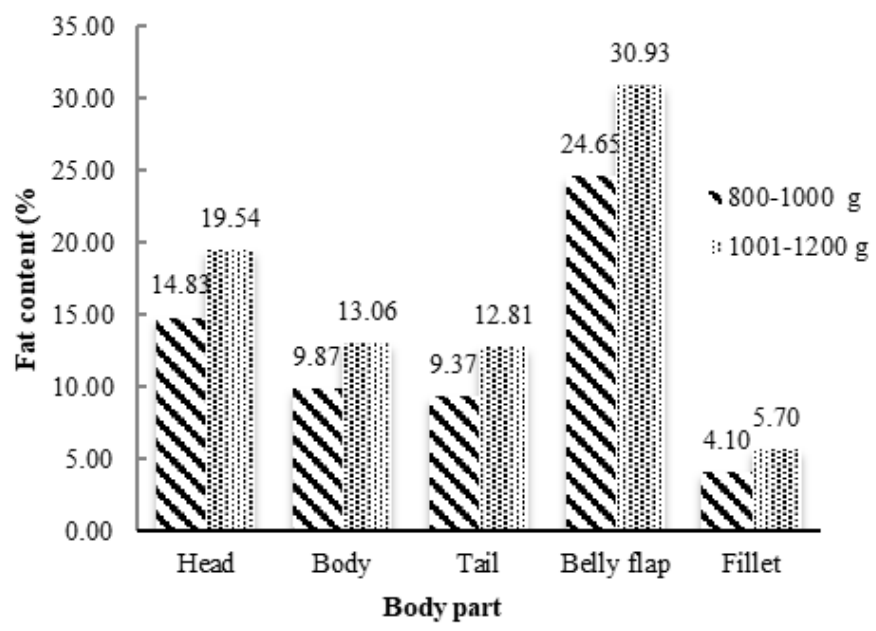

Figure 5. The fat content of Siamese catfish (Pangasius hypopthalmus) with different weight and body parts.

The fat content of head, belly flap and fillet were significantly different with other body parts, while the fat content in the tail and body is not significantly different, but significantly different with other body parts. The highest fat content in belly flap and lowest in the fillet. Belly flap part (abdominal muscle) has the highest fat content among other fish body part because catfish have part of abdominal fat stored in the contents of the stomach so that the content of fat content is stored in the body part of the fish (Hastarini et al., 2012). The fat content of fillet lowest due to the process filleting process in belly flap part, skin and body parts containing fat was removed (Suryaningrum et al., 2010). Everybody part of catfish has different fat content (Ridwan, 2010).

\subsubsection{Fatty acid}

Fatty acid profiles were identified as 23 fatty acids in body parts of catfish with different weight of fish (800$1000 \mathrm{~g}$ and 1001-1200 g) shown in Table 1. Fatty acids consist of 10 types of saturated fatty acids (SFA) and 13 types of unsaturated fatty acids. Unsaturated fatty acids found in catfish are 5 types of monounsaturated fatty acid (MUFA) and 8 types of polyunsaturated fatty acids (PUFA). This result showed the difference of fatty acid composition on body parts of catfish (head, body, tail, belly flap and fillet) with 800-1000 g and 1001-1200 g. According to Ridwan (2010), catfish with the weight of $1000 \mathrm{~g}$ showed different fatty acid composition in body parts with total fatty acid $22627.8 \mathrm{mg} / 100 \mathrm{~g}$ (head), $59811.6 \mathrm{mg} / 100 \mathrm{~g}$ (belly), and $81377.7 \mathrm{mg} / 100 \mathrm{~g}$ (body).

The saturated fatty acid of catfish weight of 800 $1000 \mathrm{~g}$ was relatively less than unsaturated fatty acids, whereas SFA in catfish 1001-1200 g relatively more than unsaturated fatty acids. Based on Ridwan (2010), unsaturated fatty acids of catfish more than total saturated fatty acid with a sample weight of $1000 \mathrm{~g}$. It can be caused by differences in feed composition, time of analysis and preparation process of fish body parts. According to Nakamura et al. (2007), the fatty acid composition in catfish depends on several factors, such as season, sex, and feed during cultivation, where the fat content may vary in each part of the fish depending on fish movement, the size of the pond, and feed. The monounsaturated fatty acid of catfish 800-1000 $\mathrm{g}$ and 1001-1200 g more than the total unsaturated fatty acids. Factors affecting fatty acid composition are species, sex, sexual maturity, body size, fishing location, water temperature, food type, and season (Estiasih et al., 2009).

\subsubsection{Saturated fatty acid (SFA)}

Catfish $800-1000 \mathrm{~g}$ has the highest total of SFA in the body part $(35,13 \%)$ and lowest in fillet $(31.84 \%)$. Catfish 1001-1200 g has the highest total of SFA in the body part $(44.03 \%)$ and the lowest in the tail (37.25\%) (Table 1). The highest level of SFA identified in the body of catfish is palmitic acid (C16:0). A number of palmitic acids on body parts of catfish with the weight of $800-1000 \mathrm{~g}$ and weight 1001-1200 g. Palmitic acid contained in the body of catfish $800-1000 \mathrm{~g}$ in belly flap, whereas with the weight of 1001-1200 g in the body part. Ridwan (2010) said that the highest SFA content contained in catfish was palmitic acid and found in belly part. According to Osman et al. (2007), palmitate is the most saturated fatty acid present in fish oil. The amount of palmitic acid in fish, which is $15-50 \%$ of all the fatty acids. Palmitate (C16:0) is saturated fatty acid having C atom greater than 12 or also called long chain fatty acids (LCFA) (Salimon and Rahman, 2008). Palmitic acids are the basic components of fat-forming systems in the living organism. In general, the high palmitic acid will be able to convert the fatty fish into semi-solid or solid at room temperature. The palmitic acid may increase the risk of atherosclerosis, cardiovascular, and stroke. Palmitic acid is used as raw material for shampoo, soft soap, and cream (Anggraini and Edison, 2015).

\subsubsection{Unsaturated fatty acid}

Total unsaturated fatty acids identified in catfish 800 $-1000 \mathrm{~g}$ more than saturated fatty acid, while unsaturated fatty acids of catfish 1001-1200 g were less than saturated fatty acid (Table 1). The results of this study showed total unsaturated fatty acids of catfish 800-1000 g greater than 1001-1200 g. Unsaturated fatty acids relatively high in fish is caused by the unsaturated fatty acids are more easily metabolized by the fish compared with saturated fatty acids (Anggraini and Edison, 2015). Unsaturated fatty acids also have beneficial to reduce total cholesterol and LDL-cholesterol contained in the 
Table 1. Fatty acid compositions of Siamese catfish (Pangasius hypophthalmus).

\begin{tabular}{|c|c|c|c|c|c|c|c|c|c|c|}
\hline \multirow{2}{*}{ Fatty acid } & \multicolumn{5}{|c|}{ Catfish with $800-1000 \mathrm{~g}$ weight $(\%)$} & \multicolumn{5}{|c|}{ Catfish with 1001-1200 g weight (\%) } \\
\hline & Head & Body & Tail & Belly & Fillet & Head & Body & Tail & Belly & Fillet \\
\hline \multicolumn{11}{|c|}{ Saturated Fatty Acid (SFA) } \\
\hline Lauric $(\mathrm{C} 12: 0)$ & 0.04 & 0.04 & 0.03 & 0.05 & 0.04 & 0.07 & 0.07 & 0.06 & 0.07 & 0.07 \\
\hline Myristic C14:0 & 2.11 & 2.26 & 2.17 & 2.18 & 1.97 & 4.35 & 4.42 & 3.65 & 4.17 & 3.95 \\
\hline Pentadecanoic (C15:0) & 0.11 & 0.11 & 0.10 & 0.11 & 0.10 & 0.08 & 0.09 & 0.08 & 0.09 & 0.09 \\
\hline Palmitic (C16:0) & 23.97 & 24.53 & 24.05 & 24.56 & 22.16 & 31.83 & 32.76 & 27.55 & 31.22 & 29.89 \\
\hline Heptadecanoic (C17:0) & 0.16 & 0.15 & 0.15 & 0.16 & 0.15 & 0.09 & 0.10 & 0.09 & 0.09 & 0.1 \\
\hline Stearic $(\mathrm{C} 18: 0)$ & 7.64 & 7.80 & 7.62 & 7.75 & 7.18 & 6.15 & 6.37 & 5.60 & 6.09 & 5.97 \\
\hline Arachidic (C20:0) & 0.13 & 0.12 & 0.12 & 0.13 & 0.12 & 0.13 & 0.14 & 0.13 & 0.13 & 0.14 \\
\hline Behenate (C22:0) & 0.05 & 0.06 & 0.05 & 0.06 & 0.06 & 0.04 & 0.05 & 0.05 & 0.04 & 0.04 \\
\hline Tricosanoate $(\mathrm{C} 23: 0)$ & 0.00 & 0.02 & 0.02 & 0.02 & 0.02 & 0.00 & 0.00 & 0.00 & 0.00 & 0.00 \\
\hline Lignoceric (C24:0) & 0.04 & 0.04 & 0.04 & 0.03 & 0.04 & 0.03 & 0.03 & 0.04 & 0.03 & 0.04 \\
\hline SFA & 34.25 & 35.13 & 34.35 & 35.05 & 31.84 & 42.77 & 44.03 & 37.25 & 41.93 & 40.29 \\
\hline \multicolumn{11}{|c|}{ Monounsaturated Fatty Acid (MUFA) } \\
\hline Myristoleic (C14:1) & 0.00 & 0.02 & 0.00 & 0.00 & 0.00 & 0.03 & 0.02 & 0.02 & 0.02 & 0.02 \\
\hline Palmitoleic (C16:1) & 0.71 & 0.71 & 0.69 & 0.71 & 0.66 & 0.69 & 0.73 & 0.67 & 0.70 & 0.70 \\
\hline Elaidat (C18:1n9) & 0.19 & 0.13 & 0.12 & 0.13 & 0.17 & 0.12 & 0.12 & 0.10 & 0.12 & 0.11 \\
\hline Oleate $(\mathrm{C} 18: \ln 9)$ & 31.22 & 31.93 & 31.06 & 31.99 & 29.09 & 31.81 & 33.60 & 28.58 & 32.11 & 30.31 \\
\hline cis-11-Eiokosenoate (C20:1) & 0.73 & 0.69 & 0.69 & 0.72 & 0.65 & 0.53 & 0.59 & 0.55 & 0.57 & 0.72 \\
\hline MUFA & 32.85 & 33.48 & 32.56 & 33.55 & 30.57 & 33.18 & 35.06 & 29.92 & 33.52 & 31.86 \\
\hline n-9 & 31.41 & 32.06 & 31.18 & 32.12 & 29.26 & 31.93 & 33.72 & 28.68 & 32.23 & 30.42 \\
\hline \multicolumn{11}{|c|}{ Polyunsaturated Fatty Acid (PUFA) } \\
\hline Linoleic $(\mathrm{C} 18: 2 \mathrm{n} 6)$ & 9.82 & 10.15 & 10.01 & 10.43 & 9.33 & 5.25 & 5.84 & 5.10 & 5.40 & 5.15 \\
\hline$\gamma$-Linolenic $(\mathrm{C} 18: 3 \mathrm{n} 6)$ & 0.18 & 0.18 & 0.17 & 0.18 & 0.16 & 0.26 & 0.27 & 0.25 & 0.25 & 0.24 \\
\hline$\alpha$-Linolenic (C18:3n3) & 0.50 & 0.54 & 0.51 & 0.54 & 0.51 & 0.18 & 0.19 & 0.19 & 0.18 & 0.23 \\
\hline cis-11,14-Eicosadienoic (C20:2) & 0.40 & 0.40 & 0.38 & 0.40 & 0.37 & 0.19 & 0.22 & 0.21 & 0.23 & 0.00 \\
\hline $\begin{array}{l}\text { cis-8,11,14-Eicosatrienoic } \\
\text { (C20:3n6) }\end{array}$ & 0.55 & 0.57 & 0.56 & 0.57 & 0.53 & 0.43 & 0.46 & 0.47 & 0.45 & 0.41 \\
\hline Arachidonic (C20:4n6) & 0.31 & 0.34 & 0.35 & 0.32 & 0.30 & 0.31 & 0.29 & 0.34 & 0.29 & 0.26 \\
\hline $\begin{array}{l}\text { cis-5,8,11,14,17- } \\
\text { Eicosapentaenoic (C20:5n3) }\end{array}$ & 0.21 & 0.23 & 0.22 & 0.22 & 0.22 & 0.13 & 0.14 & 0.13 & 0.15 & 0.13 \\
\hline $\begin{array}{l}\text { cis-4,7,10,13,16,19- } \\
\text { Docosahexaenoic (C22:6n3) }\end{array}$ & 0.63 & 0.70 & 0.68 & 0.63 & 0.62 & 0.24 & 0.25 & 0.31 & 0.30 & 0.24 \\
\hline PUFA & 12.60 & 13.11 & 12.88 & 13.29 & 12.04 & 6.99 & 7.66 & 7.00 & 7.25 & 6.66 \\
\hline n-3 & 1.34 & 1.47 & 1.41 & 1.39 & 1.35 & 0.55 & 0.58 & 0.63 & 0.63 & 0.60 \\
\hline n-6 & 10.86 & 11.24 & 11.09 & 11.50 & 10.32 & 6.25 & 6.86 & 6.16 & 6.39 & 6.06 \\
\hline Unsaturated FA & 45.45 & 46.59 & 45.44 & 46.84 & 42.61 & 40.17 & 42.72 & 36.92 & 40.77 & 38.52 \\
\hline Fatty acid & 78.30 & 80.07 & 78.00 & 80.39 & 73.18 & 72.10 & 76.44 & 65.60 & 73.00 & 68.94 \\
\hline
\end{tabular}

blood. There are 13 types of unsaturated fatty acids in the catfish, consist of 5 types of monounsaturated fatty acids (MUFA) and 8 types of polyunsaturated fatty acids (PUFA).

\subsubsection{Monounsaturated fatty acid (MUFA)}

MUFA levels most commonly found in catfish are n9 fatty acids, namely oleic acid (C18:1). According to
Hastarini et al. (2012), waste of fillet processing of catfish Pangasius hypophthalmus and Pangasius djambal were oleic fatty acid. The oleic content of catfish $800-1000 \mathrm{~g}$ is less than 1001-1200 g. Most of the oleic acid contained in catfish 800-1000 g was found on belly flap (Ridwan, 2010). While catfish 1001-1200 g most of the oleic acid contained in the body part. Differences in oleic acid values are due to differences in 
treatment, age, fish weight, and environment. Oleic acid (omega-9; n-9) can lower LDL-cholesterol, increase HDL-cholesterol and also prevent or reduce coronary heart disease. These fatty acids also have the potential to block the production of eicosanoid compounds that are tumor growth stimulants (Hafiluddin, 2011).

\subsubsection{Polyunsaturated fatty acids (PUFA)}

The most common level of PUFA found in catfish was n-6 fatty acid, linoleic acid (C18:2). Linoleic acid is one of the most important components of body fat, in the process of growth and development (Basmal, 2010). The highest level of polyunsaturated fatty acids in catfish was linoleic fatty acids (n-6) which are dominant in the belly flap part of catfish $800-1000 \mathrm{~g}$, while $1001-1200 \mathrm{~g}$ of linoleic fatty acid are dominant in body parts. According to Osman et al. (2007), the linoleic acid of catfish 800$1000 \mathrm{~g}$ is greater than 1001-1200 g. Freshwater fish have less unsaturated fatty acid than seawater. The difference may be due to the fact that freshwater fish consume more vegetation while sea-water fish consume zooplankton rich in PUFA. Linoleic acid belongs to the polyunsaturated fatty acids that are essential for body health. Linoleic acid plays a role in growth, maintenance of cell membranes, regulation of cholesterol metabolism, lowers blood pressure, inhibits hepatic lipogenesis, lipid transport, precursors in prostaglandin synthesis, and the process of reproduction. Linoleic acid deficiency can cause dermatitis, decreased reproductive ability, growth disturbance, liver degeneration, and susceptibility to infection (Anggraini and Edison, 2015).

There are three types of n-3 fatty acids in the body of catfish which are very important and include essential fatty acids i.e. linolenic acid (C18:3), eicosapentaenoic/ EPA (C20:5), and docosahexaenoic acid/DHA (C22:6). Omega-3 (n-3) fatty acids in the body of catfish 800$1000 \mathrm{~g}$ greater than 1001-1200 g. Body parts of catfish containing omega-3 highest on the weight of $800-1000 \mathrm{~g}$ $(1.47 \%$ body part derived from $0.54 \%$ linolenic acid; $0.21 \%$ EPA; and $0.70 \%$ DHA). While the weight of 1001 $-1200 \mathrm{~g}$ contains the highest $\mathrm{n}-3$ is on the tail $(0.63 \%$ derived from $0.19 \%$ linolenic acid; $0.13 \% \mathrm{EPA}$; and $0.31 \%$ DHA). The advantages of consuming omega-3 fatty acids such as EPA and DHA are the tendency that can lower cholesterol and fat in the blood so there is no accumulation of blood vessel (Hastarini et al., 2012). EPA and DHA can prevent atherosclerosis that can prevent heart disease, also improve brain intelligence and improve vision (Ermawati and Aniek, 2013). According to Basmal (2010), the factors that cause the differences in the profile of omega- 3 fatty acids in fish that are fish habitat, type of food, and the level of fish mobility activity.

\section{Conclusion}

The difference of weight and body parts of Siamese catfish (Pangasius hypophthalmus) was significantly different $(p<0.05)$ to moisture, ash, fat, and carbohydrate. The most saturated fatty acids are identified in catfish was palmitic acid, which found in belly flap part of catfish 800-1000 g and body parts of catfish 1001-1200 g. The most of monounsaturated fatty acid (MUFA) of catfish was n-9 fatty acid (oleic acid), while polyunsaturated fatty acids (PUFAs) are fatty acids was n-6 (linoleic acid). The essential fatty acids omega $n$ -3 (linolenic acid, EPA, and DHA) not significantly different in body parts (head, body, tail, belly flap, fillet) of catfish. The most of $n-3$ of catfish with $800-1000 \mathrm{~g}$ weight.

\section{Conflict of Interest}

The authors declare no competing financial interest.

\section{Acknowledgments}

We thank Fisheries Product Technology, Faculty of Agriculture, Sriwijaya University and Indonesian Ministry of Higher Education and Research and Technology.

\section{References}

Almunady, P.T., Yohandini, H. and Gultom, J.A. (2011). Qualitative and quantitative analysis of omega-3 unsaturated fatty acid of catfish (Pangasius pangasius) fish oil by Gas Chromatography Method. Journal of Science Research, 14(4), 38-40.

Anggraini, D.K. and Edison, S. (2015). Fatty acid profiles of hoven's carp (Leptobarbus hoevenii) based on harvest time difference. Riau: University of Riau, BSc Thesis

AOAC. (2005). Official Methods of Analysis of the Association of Official Analytical Chemist. $3^{\text {rd }}$ ed. Maryland, USA: AOAC Int.

Basmal, J. (2010). Escolar fish (Lepidocybium flavobrunneum) as source of essential fatty acid. Squalen, 5(3), 109-117.

Ermawati, A.T.D. and Aniek, W. (2013). Chemical analysis of skin catfish (Pangasius pangasius) chips with difference soaking temperature. Magistra, 25 (83), 22-31.

Estiasih, T., Ahmadi, K., Nisa, C.F. and Kusumastuti, F. (2009). Optimization of purification condition omega-3 fatty acid from waste of tuna (Thunnus sp.) powdering process with urea crystallization. Journal of Technology and Food Industry, 20(2), 135-142. 
Hafiluddin. (2011). Extraction and identification bioactive of sea slug (Discodoris sp.) as antioxidant. Bogor: Bogor Agricultural University, MSc Thesis

Hafiludin., Yudhita, P. and Slamet, B. (2014). Analysis of nutrition and mud smell of milk fish (Chanos chanos) from two difference location. Journal of Marine, 7(1), 33-44.

Hastarini, E., Fardiaz, D., Irianto, H.E. and Budhijanto, S. (2012). Fish oil characterization from filleting processing waste of catfish Pangasius hypophthalmus and Pangsius djambal. Agritech, 32 (4), 403-410.

Ministry of Trade Republic of Indonesia. (2013). Catfish as natural product worthy of economic and high export potential. Warta Export, 1-19.

Nianda, T. (2008). Protein and amino acid composition of gourami (Osphronemus goramy) in various harvest time. Bogor: Bogor Agricultural University. BSc Thesis.

Osman, F., Jaswir, I., Khaza'ai, H. and Hashim, R. (2007). Fatty acid profiles of fin fish in Langkawi Island, Malaysia. Journal of Oleo Science, 56(3), 107-113. https://doi.org/10.5650/jos.56.107

Ridwan, M. (2010). Chemical and physic characterization of fish oil from head, body, and belly of catfish (Pangsius pangasius). Indralaya: Sriwijaya University. BSc Thesis.

Salimon, J. and Rahman, N.A. (2008). Fatty acid composition of selected farmed and wild fresh water fishes. Sains Malaysiana, 37(12), 149-153.

Suryaningrum, T.D. (2008). Catfish: Export potential, harvest handling, and product diversification. Squalen, 3(1), 16-23.

Suryaningrum, T.D., Ijah, M. and Evi, T. (2010). Sensory profile and nutrition value of several catfish and nasutus hybrid. Squalen, 5(2): 153-164.

Taufiqurrahman. (2008). Chemical composition and vitamin A, B1, B2, and B3 of gourami (Osphronemus goramy) meat in difference size. Bogor: Bogor Agricultural University. BSc Thesis 